\title{
Mast cells are required for experimental oral allergen-induced diarrhea
}

\author{
Eric B. Brandt, ${ }^{1}$ Richard T. Strait, ${ }^{2}$ Dan Hershko, ${ }^{3,4}$ Quan Wang, ${ }^{3,4}$ Emily E. Muntel, ${ }^{1}$ \\ Troy A. Scribner, ${ }^{1}$ Nives Zimmermann, ${ }^{1}$ Fred D. Finkelman, ${ }^{5,6}$ and Marc E. Rothenberg ${ }^{1}$ \\ ${ }^{1}$ Division of Allergy and Immunology, and \\ ${ }^{2}$ Division of Emergency Medicine, Department of Pediatrics, Cincinnati Children's Hospital Medical Center, Cincinnati, Ohio, USA \\ ${ }^{3}$ Shriner's Hospital for Children, Cincinnati, Ohio, USA \\ ${ }^{4}$ Department of Surgery and \\ ${ }^{5}$ Division of Immunology, Department of Internal Medicine, University of Cincinnati, Cincinnati, Ohio, USA \\ ${ }^{6}$ Veterans Administration Medical Center, Cincinnati, Ohio, USA
}

\begin{abstract}
Gastrointestinal allergic disorders represent a diverse spectrum of inflammatory diseases that are occurring with increasing incidence and severity. An essential question concerning these disorders is to determine the specific cells and mediators responsible for specific clinical manifestations. With this in mind, we developed a murine model of oral allergen-induced intestinal inflammation accompanied by strong Th2-associated humoral and cellular responses and focused on the immunopathogenesis of allergic diarrhea. Exposure of OVA/alum-sensitized mice to repeated doses of intragastric OVA induced genetically restricted, dose-dependent, acute diarrhea associated with increased intestinal permeability, eosinophilia, and mastocytosis. Mice developed limited systemic manifestations of anaphylaxis, even though they developed marked intestinal mucosal mast cell degranulation. Notably, experiments involving mast cell depletion (with anti-c-kit mAb), anti-IgE treatment, and FceRI-deficient mice indicated a critical effector role for mast cells in mediating allergic diarrhea. Furthermore, allergic diarrhea was dependent upon synergistic signaling induced by serotonin and platelet-activating factor (PAF), but not histamine. These results demonstrate that oral allergen-induced diarrhea associated with experimental Th2 intestinal inflammation is largely mast cell, IgE, serotonin, and PAF dependent.
\end{abstract}

J. Clin. Invest. 112:1666-1677 (2003). doi:10.1172/JCI200319785.

\section{Introduction}

Gastrointestinal allergic diseases, which involve several distinct clinical entities including food anaphylaxis and eosinophil-associated gastrointestinal disorders, have dramatically increased in prevalence over the last several decades (1-3). Whereas allergic responses in the gastrointestinal tract were relatively uncommon several decades ago, recent studies have found that $2-6 \%$ of the population currently suffers from food anaphylaxis (1). These often debilitating diseases are characterized by a wide array of manifestations, including elevated levels of IgE (total and antigen specific), eosinophilia, gastrointestinal dysfunction (e.g., vomiting and diarrhea), and/or systemic responses (e.g., hypotension and bronchospasm). A central question to

Received for publication August 12, 2003, and accepted in revised form September 30, 2003.

Address correspondence to: Marc E. Rothenberg, Division of Allergy and Immunology, Department of Pediatrics, Cincinnati Children's Hospital Medical Center, 3333 Burnet Avenue, Cincinnati, Ohio 45229, USA. Phone: (513) 636-7210; Fax: (513) 636-3310; E-mail: Rothenberg@cchmc.org.

Conflict of interest: The authors have declared that no conflict of interest exists.

Nonstandard abbreviations used: 5 -hydroxytryptamine (5-HT); mucosal mast cell proteases-1-9 (MMCP-1-9); platelet-activating factor (PAF); ribonuclease protection assay (RPA); anti-IgE Ab (EM-95); major basic protein (MBP); anti-c-kit Ab (ACK2). be explored regarding gastrointestinal allergic disorders is our understanding of the molecular and cellular basis for each distinct response.

It has been generally assumed that the pathophysiology of gastrointestinal allergy is similar to that of allergic disorders involving other tissues (4); however, this may not be the case. For example, in the case of food anaphylaxis, patients often have gastrointestinal-specific rather than systemic complaints, and patients rarely have detectable plasma levels of mast cell proteases (tryptase) (5-7) that are commonly elevated in other forms of systemic anaphylaxis (e.g., drug or venom allergy) (8). Even in the extensively studied case of food anaphylaxis, however, the mechanisms responsible for end organ involvement have not been clearly elucidated (9). Elevated levels of gastrointestinal mast cells and eosinophils are often present in these patients (10). Numerous mediators derived from these cells, including vasoactive amines (e.g., histamine and serotonin [5-hydroxytryptamine (5-HT)]), proteases (mucosal mast cell proteases-1-9 [MMCP-1-9]), leukotrienes, prostaglandins, platelet-activating factor (PAF), and a large array of cytokines, have been reported to be released during anaphylaxis (9-12), but the role of each of these mediators in specific manifestations of gastrointestinal disease is not well understood. In our previous studies, we have identified an effector role for eosinophils in the development of certain fea- 
tures of experimental gastrointestinal allergy in mice (e.g., gastromegaly and weight loss) (13). Our experimental regime (involving enteric-coated allergen microbeads), however, did not induce acute responses such as allergen-induced diarrhea.

Here we aimed to identify the mechanism responsible for oral allergen-induced diarrhea, a classic clinical feature of numerous gastrointestinal allergic disorders (e.g., food allergy and eosinophil-associated gastrointestinal disorders). Accordingly, we developed a murine model of oral allergen-induced intestinal inflammation associated with strong local and systemic Th2 responses, intestinal eosinophilia and mastocytosis, and, importantly, acute diarrhea. Experiments involving mast cell depletion and/or neutralization were completely effective in curtailing the allergic diarrhea. Furthermore, diarrhea was largely IgE/FcERI mediated and, unlike systemic antigen-induced anaphylaxis, did not involve IgG receptors. In addition, allergic diarrhea was largely serotonin and PAF dependent, whereas systemic anaphylaxis in the same animals was predominantly histamine dependent. Finally, we demonstrate that gastrointestinal hypersensitivity does not threaten mouse survival, but primes for a lethal allergic response following systemic allergen exposure.

\section{Methods}

Animals. BALB/c and C57Bl/ 6 mice are obtained from the National Cancer Institute (Bethesda, Maryland, USA). FcERI-deficient mice (BALB/c background) were a gift from J.-P. Kinet (Beth Israel Deaconess Medical Center, Boston, Massachusetts, USA), IL-5 transgenic mice were backcrossed for ten generations into the BALB/c background (14), and the IL-5/eotaxin-1 double-deficient mice (BALB/c background) were generated by mating $\mathrm{F}_{1}$ crosses between the IL- 5 and eotaxin-1-deficient mice (14). All mice were housed according to institutional guidelines. Water was available continuously through automatic ports, and a commercial mouse diet was provided ad libitum. Experiments were performed on age- and gendermatched mice (6-8 weeks old).

Protocol. Mice were sensitized twice, 2 weeks apart, with $50 \mu$ g of OVA (grade V, A-5503; Sigma-Aldrich, St. Louis, Missouri, USA) in the presence of $1 \mathrm{mg}$ of aluminum potassium sulfate adjuvant [alum: $\mathrm{AIK}\left(\mathrm{SO}_{4}\right)_{2}-$ $\left.12 \mathrm{H}_{2} \mathrm{O}\right]$ (A-7210; Sigma-Aldrich) by intraperitoneal injection. Two weeks later, mice were held in the supine position three times a week (every other day) and orally administered $250 \mu \mathrm{l}$ of sterile saline that contained up to $50 \mathrm{mg}$ of OVA. Before each intragastric challenge, mice were deprived of food for 3-4 hours with the aim of limiting antigen degradation in the stomach. Challenges were performed with intragastric feeding needles (01-290-2B; Fisher Scientific Co., Pittsburgh, Pennsylvania, USA). Diarrhea was assessed by visually monitoring mice for up to 1 hour following intragastric challenge. Mice demonstrating profuse liquid stool were recorded as diarrhea-positive animals. Sometimes multiple observers blinded to the experimental protocol scored the occurrence of diarrhea.

Intestinal permeability. In vitro permeability was measured in Ussing chambers as described previously (15). Briefly, two jejunum segments per mouse were opened along the mesenteric border, rinsed, and pinned as intact sheets between siliconized Ussing half chambers. The electrical potential difference between the mucosal and serosal surface, an indicator of tissue viability, was determined by using calomel electrodes, while electrical resistance, which is inversely related to tissue permeability, was determined by changing voltage across the mounted intestinal wall and measuring the change in short-circuit current. After the preparation had stabilized for 20 minutes and baseline potential difference and resistance had been established, FITC-dextran (2.2 $\mathrm{mg} / \mathrm{ml}$, molecular mass $4.4 \mathrm{kDa}$; Sigma-Aldrich) and HRP $(0.1 \mathrm{mg} / \mathrm{ml}$, molecular mass $40 \mathrm{kDa}$; SigmaAldrich) were added to the mucosal reservoir. Medium $(0.25 \mathrm{ml}$ out of $5 \mathrm{ml})$ was removed from the serosal reservoir and replaced with fresh medium every 20 minutes over a period of 180 minutes for measurement of FITC-dextran and HRP.

Ribonuclease protection assay. Jejunal RNA was obtained using Trizol reagent (Life Technologies Inc., Grand Island, New York, USA) following the manufacturer's protocol. The ribonuclease protection assay (RPA) was performed by making a radioactive probe from the mCk-1b multiprobe template (Riboquant multi-probe RPA system; BD Biosciences PharMingen, San Diego, California, USA). RNA from OVA- and saline-challenged mice was then hybridized overnight with the radioactive probe, purified, and finally run on an ureaacrylamide gel at $75 \mathrm{~W}$ as described in the Riboquant protocol from BD Biosciences PharMingen.

ELISA measurements. MMCP-1 and total IgE plasma levels were measured by ELISA according to the manufacturer's instructions (respectively, Moredun Scientific, Midlothian, United Kingdom, and BD Biosciences PharMingen). Plasma OVA-specific IgE was determined by luminescence ELISA. Briefly, white nontransparent plates were coated for 2 hours with $50 \mu \mathrm{l}$ of anti-IgE Ab (EM-95; $10 \mu \mathrm{g} / \mathrm{ml}$ ), blocked with $200 \mu \mathrm{l}$ of Superblock (37545; Pierce Chemical Co., Rockford, Illinois, USA), and washed with $0.05 \%$ Tween- 20 in Tris-saline before adding serial dilutions of plasma samples ( $25 \mu \mathrm{l} /$ well). After 1 hour of incubation, plates were washed, and biotinylated OVA was added (1:1,000 dilution of 2 $\mathrm{mg} / \mathrm{ml}, 25 \mu \mathrm{l} /$ well). After 30 minutes of incubation and one wash, streptavidin-HRP (1:20,000 dilution) (Immuno Pure Streptavidin Horseradish Peroxidase Conjugated II, 21126; Pierce Chemical Co.) was added. Finally, after 30 minutes and one wash, $150 \mu \mathrm{l}$ of substrate (SuperSignal ELISA Femto Maximum Sensitivity Substrate, 37075; Pierce Chemical Co.) was added. Plates were read using the Fluoroskan luminometer (Luminoskan, Ascent software, Thermo Electron Corporation, Franklin, Massachusetts, USA). Plasma OVAspecific IgG1 and IgG2a were measured after coating 
the wells with OVA $(100 \mu \mathrm{g} / \mathrm{ml})$. Blocking was done with $10 \%$ FBS in PBS, and all washes were performed with $0.05 \%$ Tween-20 in PBS. Plasma samples were diluted 1:1,000 for IgG1 and 1:10 for IgG2a and then serially diluted 1:4. After 2 hours of incubation, plates were washed and HRP-conjugated anti-mouse IgG1 $(1: 1,000)$ (X56; BD Biosciences-PharMingen) or HRPconjugated anti-mouse IgG2a (1:1,000) (R19-15; BD Biosciences-PharMingen) was added. The OD was read at $450 \mathrm{~nm}$ within 10 minutes. Data represent mean plus or minus SEM of the plasma dilution required to obtain $\mathrm{OD}=0.6$ for IgG1 and $\mathrm{OD}=0.35$ for IgG2a. The $\mathrm{OD}=0.6$ was chosen because it is in the middle of the linear part of the curve; $\mathrm{OD}=0.35$ was selected because it was the lowest linear region for all of the detectable groups, as previously reported (13).

Quantification of blood eosinophils. Blood was diluted $(1: 10)$ in Discombe's solution prepared by mixing $5 \times$ vol 1\% wt/vol aqueous eosin Y (Fisher Scientific Co., Fair Lawn, New Jersey, USA) with $5 \times$ vol acetone and adding a $100 \times$ volume of water. For each sample, eosinophils per cubic millimeter of the hemocytometer chamber (Hausser Scientific Partnership, Horsham, Pennsylvania, USA) were counted, and the final result was expressed as the number of eosinophils per milliliter of blood.

Intestinal eosinophil and mast cell quantification. Jejunum tissue was collected $10-12 \mathrm{~cm}$ distal to the stomach, while ileum and colon samples were collected $1 \mathrm{~cm}$ proximal or distal of the cecum, respectively. All samples were fixed in 10\% formalin and processed by standard histological techniques. Eosinophils were immunostained as previously described with antiserum against mouse major basic protein (MBP) (13). Briefly, $5-\mu \mathrm{m}$ sections were quenched with $\mathrm{H}_{2} \mathrm{O}_{2}$, blocked with normal goat serum, and stained with a rabbit anti-murine eosinophil MBP antiserum (a kind gift of J. and N. Lee, Mayo Clinic, Scottsdale, Arizona, USA). The slides were washed and incubated with biotinylated goat anti-rab$\mathrm{bit} \mathrm{Ab}$ and avidin-peroxidase complex (Vectastain $\mathrm{ABC}$ Peroxidase Elite kit; Vector Laboratories, Burlingame, California, USA). The slides were then developed by nickel diaminobenzidine, enhanced with cobalt chloride to form black precipitate, and counterstained with nuclear fast red. The $5-\mu \mathrm{m}$ tissue sections were also stained for mucosal mast cells with chloroacetate esterase activity as described elsewhere (16) and lightly counterstained with hematoxylin. At least three random sections per mouse were analyzed. Quantification of stained cells per square millimeter of lamina propria was performed by morphometric analysis using the Metamorph Imaging System (Universal Imaging Corp., West Chester, Pennsylvania, USA).

Microarray bybridization. Following TRIzol purification, RNA was repurified with phenol-chloroform extraction and ethanol precipitation. Purified RNA from four saline-treated and four OVA-challenged mice were then pooled together and processed at Cincinnati Children's Hospital Medical Center Affymetrix Gene
Chip Core facility, using the murine U74Av2 GeneChip (Affymetrix, Santa Clara, California, USA) as previously described (17). Differences between saline- and allergentreated mice were also determined using the GeneSpring software (Silicon Genetics, Redwood City, California, USA). Data were normalized to saline-treated mice, and genes, present in at least one sample, were screened for a greater than twofold change over saline. A further description of the methodology, according to MIAME (minimum information about a microarray experiment) guidelines (www.mged.org/Workgroups/MIAME/ miame.html) is provided in Supplementary Data (http://www.JCI.org/cgi/content/full/112/11/1666/DC1).

$A b$ treatments. All reagents were diluted in saline to a final volume of $200 \mu \mathrm{l}$ per mouse. As previously described $(18,19)$, in order to block IgG-mediated hypersensitivity reaction, a single dose of $500 \mu \mathrm{g}$ of antiFcyRII/RIII (24G2, a rat IgG2b Ab; American Type Culture Collection, Rockville, Maryland, USA) was injected intraperitoneally 24 hours before intragastric challenge. To prevent an IgE-mediated hypersensitivity reaction, a single dose of $100 \mu \mathrm{g}$ of anti-IgE (EM-95, a rat IgG2a anti-mouse IgE mouse Ab from Zelig Eshhar, Weizmann Institute of Science, Rehovot, Israel) was administered intraperitoneally 24 hours before the sixth intragastric challenge. To prevent systemic anaphylaxis following anti-IgE injection, mice received an intravenous injection of $0.2 \mathrm{mg}$ of antihistamine (triprolidine, an $\mathrm{H} 1$ receptor antagonist from Sigma-Aldrich) 20 minutes prior to anti-IgE mAb administration. The short half-life of triprolidine allowed us to alleviate the anaphylactic reaction to EM-95 without affecting the response to intragastric OVA challenge on the following day. Mice were also pretreated with control Ab's: GL117, a rat IgG2a mouse $A b$ or J1.2, a rat IgG2b anti-mouse $A b$ (both from John Abrams, DNAX Research Institute, Palo Alto, California, USA). To deplete BALB/c mice of their mucosal mast cells, mice were administered five doses (first dose intravenously, then intraperitoneally) of $1 \mathrm{mg}$ of anti-c-kit Ab (ACK2) (20) or a control Ab (J1.2) the day before each intragastric challenge.

Antiallergic drug treatments. Drugs were all given intravenously 20-30 minutes before intragastric saline or allergen challenge, alone or in combination, resulting in a total volume of $200 \mu \mathrm{l}$ per injection. A single dose of each drug was selected based on previous publications and the manufacturer's information $(18,19)$. The reagents included $66 \mu \mathrm{g}$ CV6209, PAF receptor antagonist (Biomol Research Laboratories, Plymouth Meeting, Pennsylvania, USA) (21); $60 \mu \mathrm{g}$ mepyramine, $\mathrm{H} 1$ receptor antagonist (Tocris Cookson Ltd., Ellisville, Missouri, USA) (22); $0.2 \mathrm{mg}$ cimetadine, $\mathrm{H} 2$ receptor antagonist (Tocris Cookson Ltd.) (23); $60 \mu \mathrm{g}$ ketanserin, 5- $\mathrm{HT}_{1 \mathrm{c} / 2 \mathrm{a}}$ receptor antagonist (24) (Alexis Corp., San Diego, California, USA); 0.25 mg azasetron, 5- $\mathrm{HT}_{3}$ receptor antagonist (Y-25130, Biomol Research Laboratories) (25); and $75 \mu \mathrm{g}$ SB 203-186, 5- $\mathrm{HT}_{4}$ receptor antagonist (Tocris Cookson Ltd.).

Systemic anaphylaxis. Systemic anaphylaxis was induced by intravenous injection of OVA $(0.1-1,000 \mu \mathrm{g}$ 
a Two sensitizations
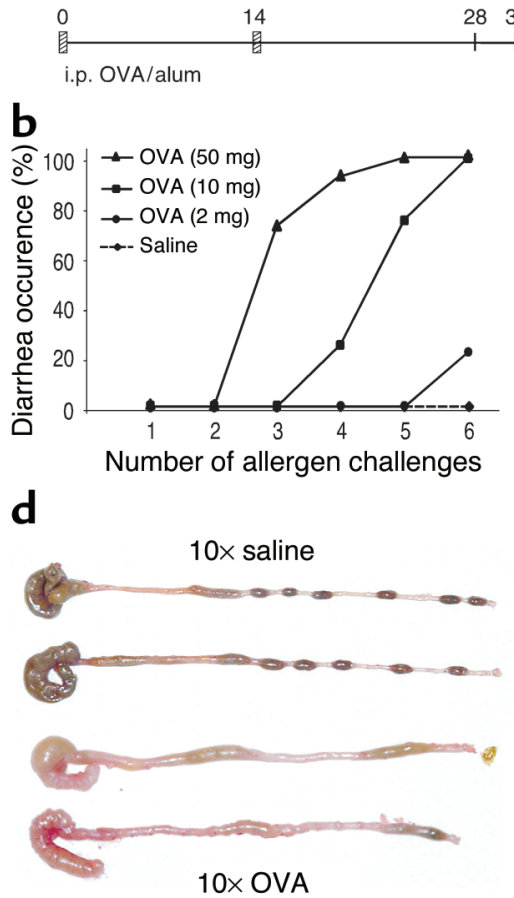

Intragastric challenges

$\begin{array}{llllllllll}28 & 30 & 32 & 35 & 37 & 39 & 42 & 44 & 46 & 49 \\ \text { days }\end{array}$

Saline or OVA (50 mg)

C

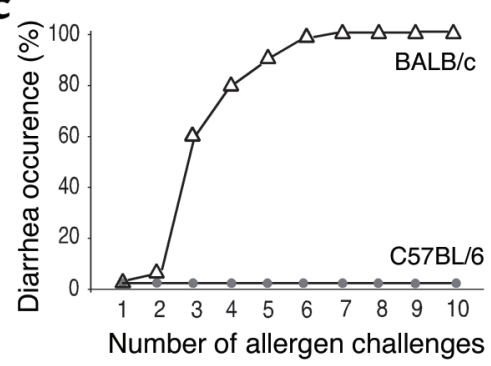

e

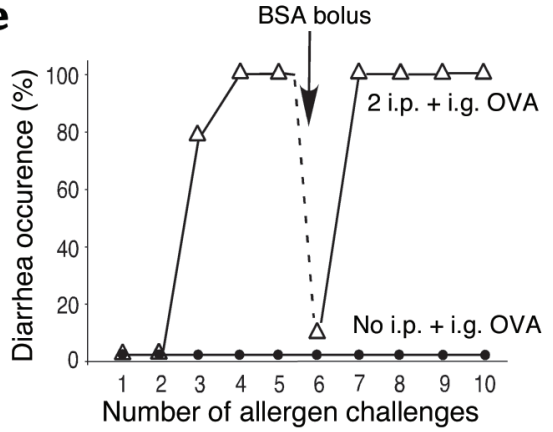

Figure 1

A murine model of allergen-induced diarrhea. (a) The time line illustrates that mice were sensitized with two OVA/alum intraperitoneal (i.p.) injections (vertical hatch mark) and subsequently treated with intragastric (i.g.) saline or OVA challenges every 2-3 days (vertical lines). (b) Diarrhea occurrence was assessed 15-45 minutes after intragastric challenges with either saline or increasing doses of OVA (2-50 $\mathrm{mg}$ in $250 \mu \mathrm{l}$ of saline). (c) Diarrhea occurrence in BALB/c mice $(n=16)$ was compared with $\mathrm{C} 57 \mathrm{BI} / 6$ mice $(n=8)$ following ten intragastric OVA challenges $(50 \mathrm{mg})$. (d) Representative photograph of the cecum and colon of BALB/c mice 60 minutes after ten intragastric saline or OVA challenges (upper and lower two samples, respectively). (e) Nonsensitized mice $(n=8)$ or OVA/alum-sensitized mice $(n=15)$ were treated with repeated doses of intragastric OVA (50 mg). Following five doses of OVA, sensitized mice were challenged with BSA (50 mg) as a control before resuming OVA challenges. in normal saline in a final volume of $200 \mu \mathrm{l}$ ) in OVA/alum-sensitized mice. Rectal and oral temperatures were measured with a Digital Thermocouple Thermometer (BAT-12; Physitemp Instruments Inc., Clifton, New Jersey, USA) as described previously (19). To block clinical manifestations of anaphylaxis, mice were treated with various combinations of antihistaminic drugs (mepyramine and cimetadine), antiserotonin drugs (either ketanserin or azasetron and SB 203 186), and anti-PAF (CV6209), as described above.

Statistical analysis. Data are expressed as mean plus or minus SEM. Statistical significance comparing different sets of mice was determined by the Student $t$ test.

\section{Results}

Oral allergen-induced diarrhea. We aimed to develop a model of antigen-induced eosinophil-associated gastrointestinal hypersensitivity characterized by acute diarrhea. In previous studies we reported that oral administrations of OVA (up to $2 \mathrm{mg}$ ) in the form of enteric-coated beads (but not soluble OVA) was effective at inducing a Th2-associated gastrointestinal response (13). Although this experimental regime induced several features of chronic gastrointestinal allergy, the mice did not undergo oral allergen-induced diarrhea. Based on a previous publication (26), we modified our experimental regime by sensitizing mice with two OVA/alum intraperitoneal injections separated by 2 weeks and by then administering relatively higher amounts of soluble OVA (2-250 $\mathrm{mg}$ ) by repeated intragastric delivery (Figure 1a). Following this protocol, mice developed diarrhea 15-45 minutes after the third OVA challenge (Figure 1b). In BALB/c mice, dose-response experiments revealed that there was a plateau in diarrhea induction between doses of 50 and $250 \mathrm{mg}$ (data not shown), leading us to use $50 \mathrm{mg}$ of OVA per challenge for subsequent experiments. Although BALB/c mice started developing diarrhea acutely after the third intragastric challenge, $\mathrm{C} 57 \mathrm{Bl} / 6$ mice were resistant to up to ten intragastric OVA challenges (Figure 1c). Diarrhea was also noted by direct observation of the colon and cecum; the liquid stool observed following OVAinduced diarrhea contrasts with the solid pellets seen in the distal colon of saline-challenged mice (Figure 1d).

To determine if the intraperitoneal sensitization was required for OVA-induced diarrhea, we subjected nonsensitized BALB/c mice to ten intragastric OVA challenges; this failed to induce any signs of diarrhea (Figure $1 \mathrm{e})$. We were next interested in determining if persistence of diarrhea was antigen specific. To test this hypothesis, mice that had already developed diarrhea during two or three consecutive OVA challenges were given an intragastric BSA bolus (Figure 1e). These mice failed to develop acute diarrhea. Following subsequent intragastric OVA exposure, however, diarrhea was reestablished. These results, along with the fact that nonsensitized mice did not develop diarrhea, demonstrate that the observed diarrhea was not solely the result of an osmotic load in the gut, but rather an antigen-specific acute immunological response. In conclusion, our results demonstrate that three to four intragastric OVA challenges $(50 \mathrm{mg})$ in OVA/alum-sensitized BALB/c mice induces antigen-specific diarrhea by a genetically regulated mechanism.

Allergic diarrhea is not directly associated with hypothermia, but primes for systemic anaphylaxis. During systemic anaphylaxis, a dramatic drop in whole body temper- 

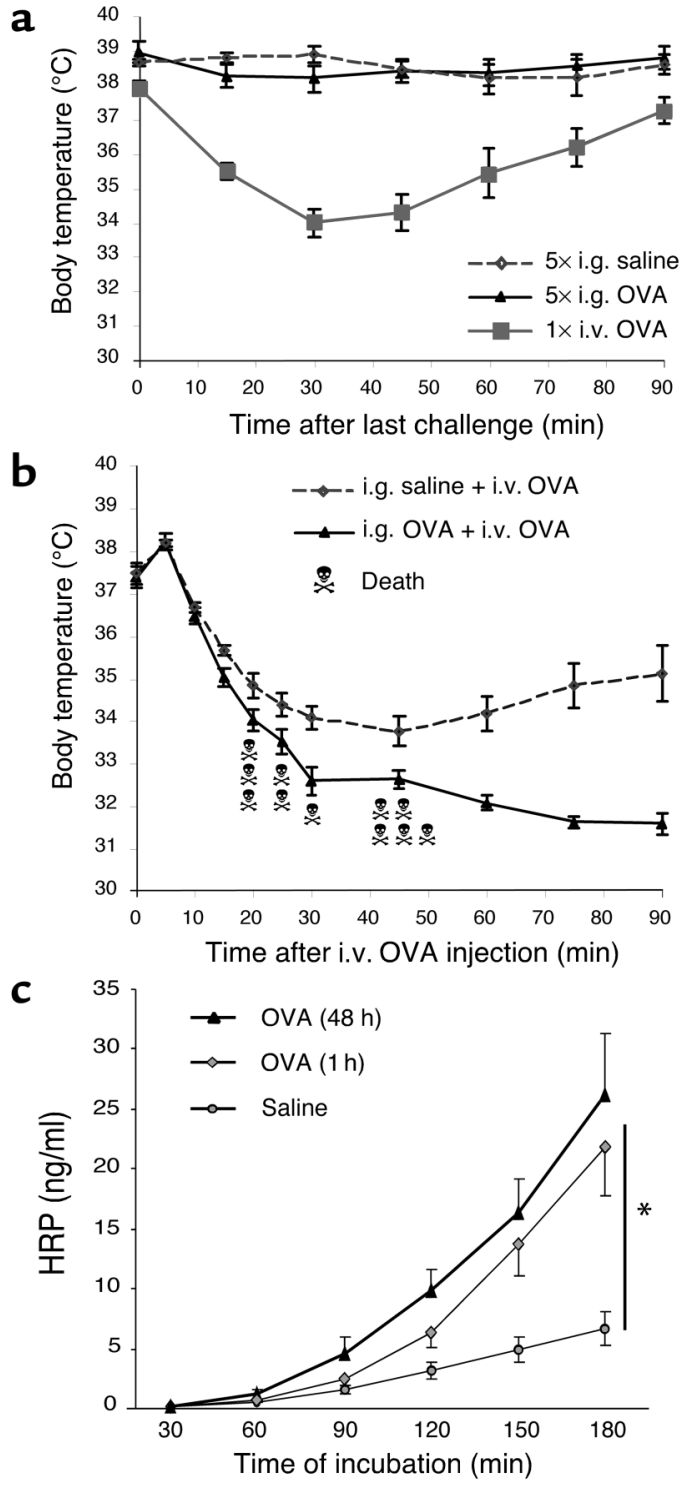

Figure 2

Clinical features associated with allergic diarrhea. (a) Anaphylaxis was assessed by measuring hypothermia following either five intragastric saline or OVA challenges. As a control, systemic anaphylaxis was induced in OVA/alum-sensitized mice by an i.v. OVA $(100 \mu \mathrm{g})$ injection. Body temperatures are expressed in degrees Celsius as mean $\pm \operatorname{SEM~(~} n=8$ mice/group). (b) Systemic anaphylaxis was also induced in OVA/alum-sensitized and saline- $(n=7)$ or OVA- $(n=13)$ intragastric challenged mice by an intravenous injection of OVA (100 $\mu \mathrm{g}$ ). Death occurred only in the intragastric OVA group (11 out of 13 mice). (c) Jejunum segments were isolated 1 hour after five to six saline or OVA challenges, and intestinal permeability to HRP was measured in an Ussing chamber over a 180-minute period (mean $\pm \mathrm{SEM} ; n=8$ mice/group; ${ }^{*} P=0.0012$ ).

ature is commonly observed $(18,19,22)$; however, this was consistently not observed during the experimental regime (Figure 2a). As a control, mice undergoing systemic anaphylaxis (elicited by intravenous allergen) developed marked hypothermia (Figure 2a). We were also interested in determining the effect of the experimental regime on the development of sub- sequent systemic anaphylaxis. To address this, we intravenously injected OVA in OVA/alum-sensitized mice that had previously been exposed to five intragastric doses of OVA or saline. Hypothermia was significantly more severe in mice previously intragastrically challenged with OVA compared with salinechallenged mice (Figure 2b). Notably, lethal anaphylactic shock occurred only in mice that had previously developed gastrointestinal allergy (Figure $2 \mathrm{~b})$. Collectively, these results suggest that intragastric OVA does not directly induce systemic anaphylaxis, but rather primes for more severe expression of anaphylaxis following antigen challenge.

Allergen-induced diarrhea is accompanied by enhanced intestinal permeability. We were next interested in determining the correlation between allergen-induced diarrhea and changes in intestinal permeability. Original studies suggested that allergic diarrhea was induced by enhanced intestinal ion secretion associated with decreased gut permeability (27). Recent studies, however, have challenged this view by demonstrating that inflammatory responses are often associated with enhanced intestinal permeability $(27,28)$. We therefore examined intestinal permeability by analyzing HRP and FITC-dextran transport in jejunal segments ex vivo. Compared with control mice, OVA-challenged mice had increased intestinal permeability to HRP (Figure 2c) and FITC-dextran (data not shown). For example, the amount of HRP that migrated through the jejunum layer was significantly increased 1 hour after OVA challenge compared with jejunum samples from salineexposed animals $(21.8 \pm 4.0 \mathrm{ng} / \mathrm{ml}$ versus $6.7 \pm 1.4$ $\mathrm{ng} / \mathrm{ml}$ at 180 minutes; $P=0.0012$ ). Furthermore, the antigen-induced increased permeability persisted at 48 hours ( $26.3 \pm 5.1$ at 180 minutes; $P=0.0001$ ). Finally, intestinal permeability was similar between nonsensitized control mice and mice that were sensitized but not OVA challenged (data not shown), suggesting that the observed increase in intestinal permeability was induced by the intragastric OVA challenge rather than by the sensitization alone.

$T h 2$ immune response. We were next interested in determining if OVA-induced diarrhea was associated with other immunological manifestations of allergy, such as Th2 cytokine and $\mathrm{Ab}$ production (e.g., IgE and IgG1) and eosinophilia. To assess the local cytokine profile, mRNA purified from jejunum samples was analyzed by RPA (Figure 3a). IL-10 and IFN- $\gamma$ mRNA were detected in all jejunum samples regardless of challenge number, in contrast to IL-4 and IL-13 mRNA, which were only detectable after two or three OVA challenges (Figure 3a). Furthermore, while IFN- $\gamma$ mRNA levels were unchanged between saline- and OVA-challenged mice, IL-4, IL-10, and IL-13 mRNA were increased in OVA-challenged mice (Figure 3a). The finding that these Th2 cytokines were already induced in OVA-challenged BALB/c mice following the second and third intragastric challenge suggests that this strong local Th2 environment may be neces- 
a $2 x$
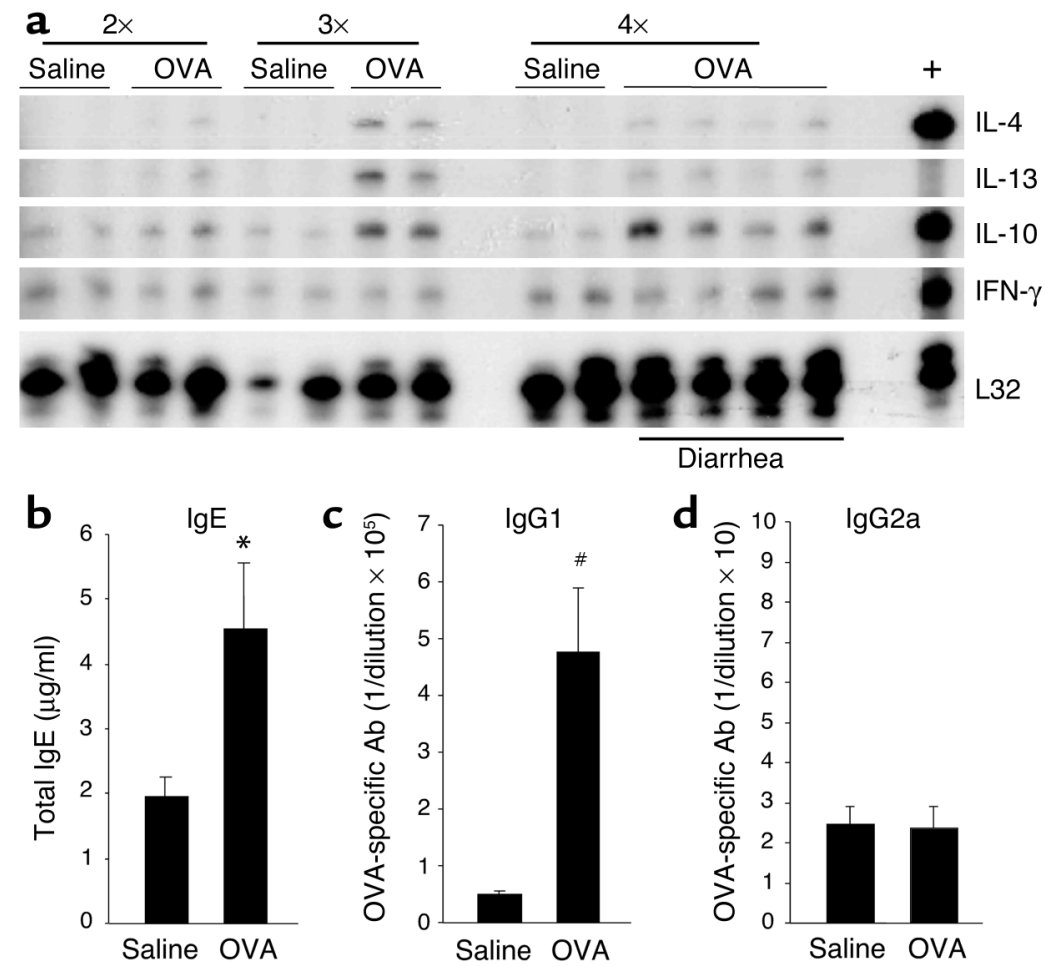

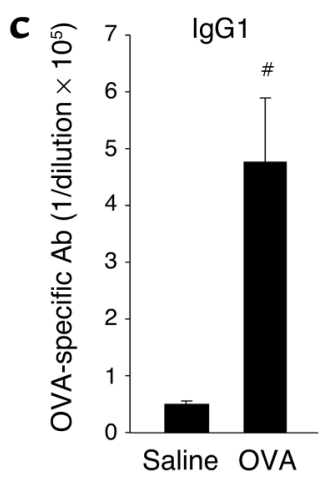

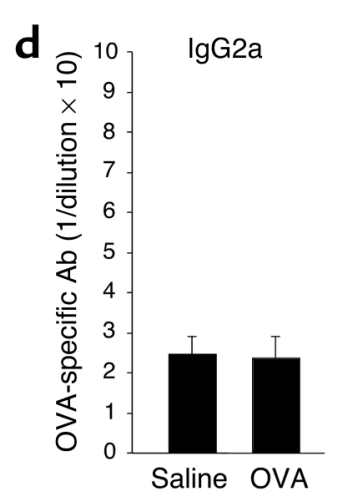

\section{Figure 3}

Intestinal and systemic Th2 responses. (a) Jejunum samples were collected 60 minutes after two, three, or four saline or OVA challenges and analyzed by RPA for Th1/Th2 cytokine expression. The positive control $(+)$ (see Methods) expressed IL-4, IL-10, and IFN- $\gamma$. The housekeeping gene L32 was used as a control for RNA loading. Total IgE (b), OVA-specific IgG1 (c), and IgG2a (d) plasma titers were measured following OVA or saline challenges (mean \pm SEM; $n=8-11$ mice/group; ${ }^{*} P=0.020$; ${ }^{\#} P=0.003$.)

ly more blood eosinophilia following OVA challenges, whereas IL-5/eotaxin-1 double-deficient mice had barely detectable blood eosinophilia (Figure 4a; $P<0.005$ ). In the jejunum (Figure $4, \mathrm{~b}$ and $c$ ), the number of eosinophils was significantly higher in IL-5 transgenic mice $(P=0.005)$ and significantly lower in IL-5/eotaxin-1 double-deficient mice $(P=0.004)$ compared with $\mathrm{BALB} / \mathrm{c}$ mice (following OVA and saline exposure). Surprisingly, oral allergen-induced diarrhea occurred at similar levels in all sary for the observed diarrhea following the fourth OVA challenge. Following allergen-induced diarrhea, plasma levels of total IgE were significantly higher in OVA-challenged mice compared with saline-challenged mice (Figure $3 b ; P=0.02$ ). Additionally, there was a large increase in OVA-specific IgE by the sensitization alone and a modest increase by the intragastric allergen challenges (undetectable levels, $45 \pm 5$, and $62 \pm 11$ in unsensitized OVA-challenged, sensitizedsaline challenged, and sensitized OVA-challenged mice, respectively (data expressed as reciprocal plasma dilution, mean \pm SEM; $n=4-6$ mice). OVA-specific IgG1 Ab plasma titers were significantly higher following OVA challenges compared with saline challenges (Figure $3 c ; P=0.003$ ). Furthermore, OVA-specific $\operatorname{IgG} 1$ and total $\operatorname{IgE}$ were increased after five allergen challenges compared with before allergen challenge (data not shown). Taken together with the almost undetectable OVA-specific IgG2a titers (Figure $3 \mathrm{~d})$, these data suggest that the Th2 profile, induced by sensitization with OVA/alum, was further amplified by the repeated intragastric OVA.

Eosinophils are increased but not required for orally induced diarrhea. It has been postulated that eosinophil recruitment and degranulation in the gastrointestinal tract may contribute to allergic diarrhea (26), possibly by directly affecting mast cells (29). To test this hypothesis, we compared the severity of diarrhea in genetically engineered mice that have variable levels of eosinophils, such as IL-5 transgenic mice (with elevated levels of eosinophils) and IL-5/eotaxin-1 double-deficient mice (with depressed levels of eosinophils) $(2,30)$. Indeed, compared with control mice, IL-5 transgenic mice had significant- three groups of mice (Figure 4d), providing strong evidence that eosinophils were not involved in this manifestation of the experimental disease.

Microarray dissection of experimental intestinal anaphylaxis. To further understand the pathogenesis of experimental gastrointestinal allergic responses, we examined global mRNA expression patterns in the gastrointestinal tract of saline- and OVA-challenged $\mathrm{BALB} / \mathrm{c}$ mice, using the Affymetrix chip U74Av2 that contains oligonucleotide probe sets representing 12,423 genetic elements. Comparison of allergen-challenged mice with saline-challenged mice revealed a decrease (less than 0.5 -fold change over saline) in 53 genes and an increase (greater than twofold change over saline) in 530 genes (Figure 5a). Among the ten genes with the highest fold increase over saline levels, we found the two mast cell proteases classically associated with mucosal mast cells (Figure 5a): MMCP-1 (40-fold increase) and MMCP-2 (17-fold increase). The increase in MMCP-1 transcript levels in the jejunum was substantiated by an impressive 5,000-fold increase in MMCP-1 plasma levels in OVAchallenged versus saline-challenged mice (Figure 5b). Interestingly, the other mast cell proteases (MMCP-4 to MMCP-7), which are primarily associated with connective tissue mast cells, were all undetectable on the microarray chip, with the exception of the MMCP-5 gene, which was only modestly increased (2.4-fold). Numerous other mast cell-related genes were elevated, including the FceR $\alpha$ chain (31-fold increase), heparin sulfate 3-O-sulfotransferase 1 (21-fold increase), tryptophan hydrolase (8.3-fold increase), carboxypeptidase A3 (12-fold increase), mast cell protease-like protein (5.1-fold increase), and the histidine decarboxylase 

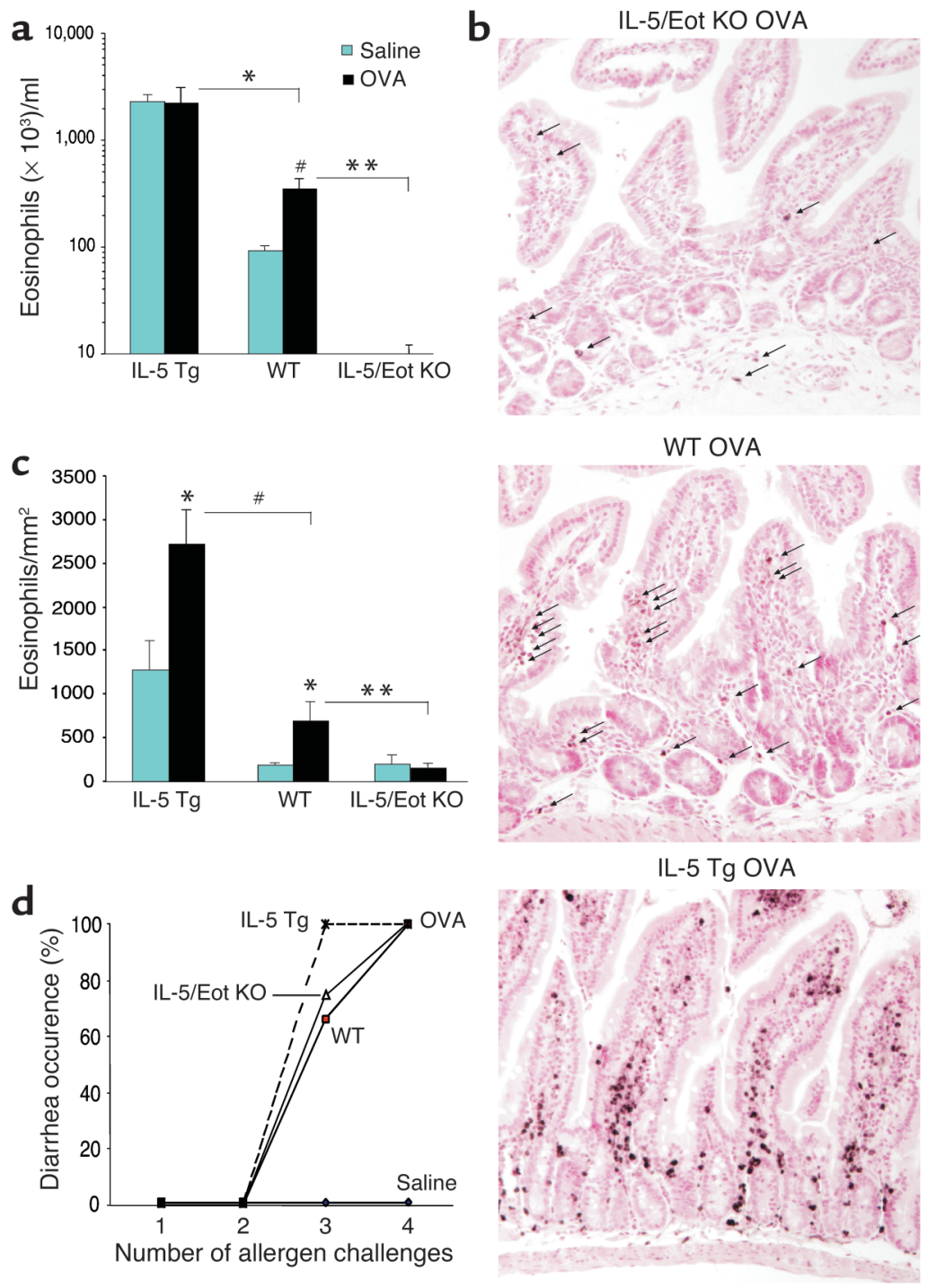

\section{Figure 4}

Role of eosinophils in allergic diarrhea. (a) Blood eosinophil levels in IL-5 transgenic ( $\mathrm{Tg}$ ) mice, IL-5/ eotaxin-1 double-deficient mice (IL-5/Eot KO), and WT BALB/c mice were assessed 72 hours after the third saline or OVA challenge (mean \pm SEM; $n=4-10$ mice; $\left.{ }^{*} P<0.0001 ;{ }^{*} P<0.004 ;{ }^{*} P=0.0035\right)$ (b) Representative jejunum section from OVA-challenged WT, IL-5 transgenic, and IL-5/eotaxin-1 double-deficient mice, immunostained with anti-MBP $A b$ as described in Methods (arrows indicate eosinophils; original magnification, $\times 125)$. (c) Jejunum eosinophil levels were assessed by morphometric analysis in IL-5 transgenic mice, IL-5/ eotaxin-1 double-deficient mice, and WT BALB/C mice (mean \pm SEM; $n=4$ mice; ${ }^{*} P<0.05 ;{ }^{\#} P=0.005$; $\left.{ }^{*} P=0.004\right)$. (d) Diarrhea occurrence in IL-5 transgenic, IL-5/eotaxin-1 double-deficient, and WT control mice following saline or OVA challenges.

strong degranulation, connective tissue mast cells were less significantly affected (Figure 5d). Mast cell levels were maximal in the small intestine compared with the large intestine with $356 \pm 9.2$ mast cells $/ \mathrm{mm}^{2}$ in the upper jejunum, $207 \pm 82$ in the ileum, and $13.2 \pm 9.4$ in the colon (Figure 5e). Interestingly, this trend was present in saline-challenged mice with $45.0 \pm 9.2$ mast cells $/ \mathrm{mm}^{2}$ in the jejunum, $9.3 \pm 4.2$ in the ileum, and $1.6 \pm 2.3$ in the colon. Furthermore, mast cell numbers following OVA challenge continued to increase between challenge three and five (Figure 5f) and peaked between challenge five and ten. Taken together, these data indicate that OVA challenge induces extensive mucosal

cluster (2.9-fold increase). Taken together, these data suggest a important potential role for mast cells in the experimental regime.

Oral allergen induces intestinal mastocytosis. Based on the microarray results and the known mastocytosis that is commonly observed in allergic disease, we were interested in examining mast cell levels in the intestines of mice with gastrointestinal allergy. Whereas standard H\&E staining of intestinal sections did not identify appreciable mast cells, chloroacetate esterase histochemistry readily detected intestinal mast cells, consistent with previous publications (16). Notably, the jejunum of OVA-challenged mice contained highly increased levels of mast cells compared with salinechallenged control mice (Figure 5, $c$ and d). The majority of infiltrating mast cells showed signs of massive degranulation, with much of their cytoplasm depleted of the characteristic red chloroacetate esterase stain (Figure $5 \mathrm{~d}$ and magnified insert), consistent with the large increase in MMCP-1 plasma levels (Figure 5b). Interestingly, while mucosal mast cells showed signs of mast cell hyperplasia and degranulation.

Mast cells are required for allergen-induced diarrhea. The strong association between degranulating mucosal mast cells and diarrhea onset suggested a direct causal relationship. To prove this, we depleted intestinal mast cells by repeated treatment with an anti-c-kit Ab (ACK2) (20) before each challenge, as shown in Figure 6a. We validated the efficiency of our treatment by counting jejunum mast cell numbers and MMCP-1 plasma levels in mice treated with ACK2 or a control Ab (J1.2). Remarkably, no chloroacetate esterase-positive mast cells (both mucosal and connective tissue mast cells) were found in jejunum sections, and almost no MMCP1 was detected in plasma samples from ACK2-treated mice (Figure 6, b and c). Importantly, in the absence of mast cells, mice did not develop allergic diarrhea (Figure 6d). Furthermore, intestinal permeability to HRP in the ACK2-treated mice was significantly decreased compared with J1.2-treated mice (Figure 6e; $P=0.01$ ). Collectively, these findings strongly implicate mucosal mast cells as being critically involved in allergic diarrhea. 

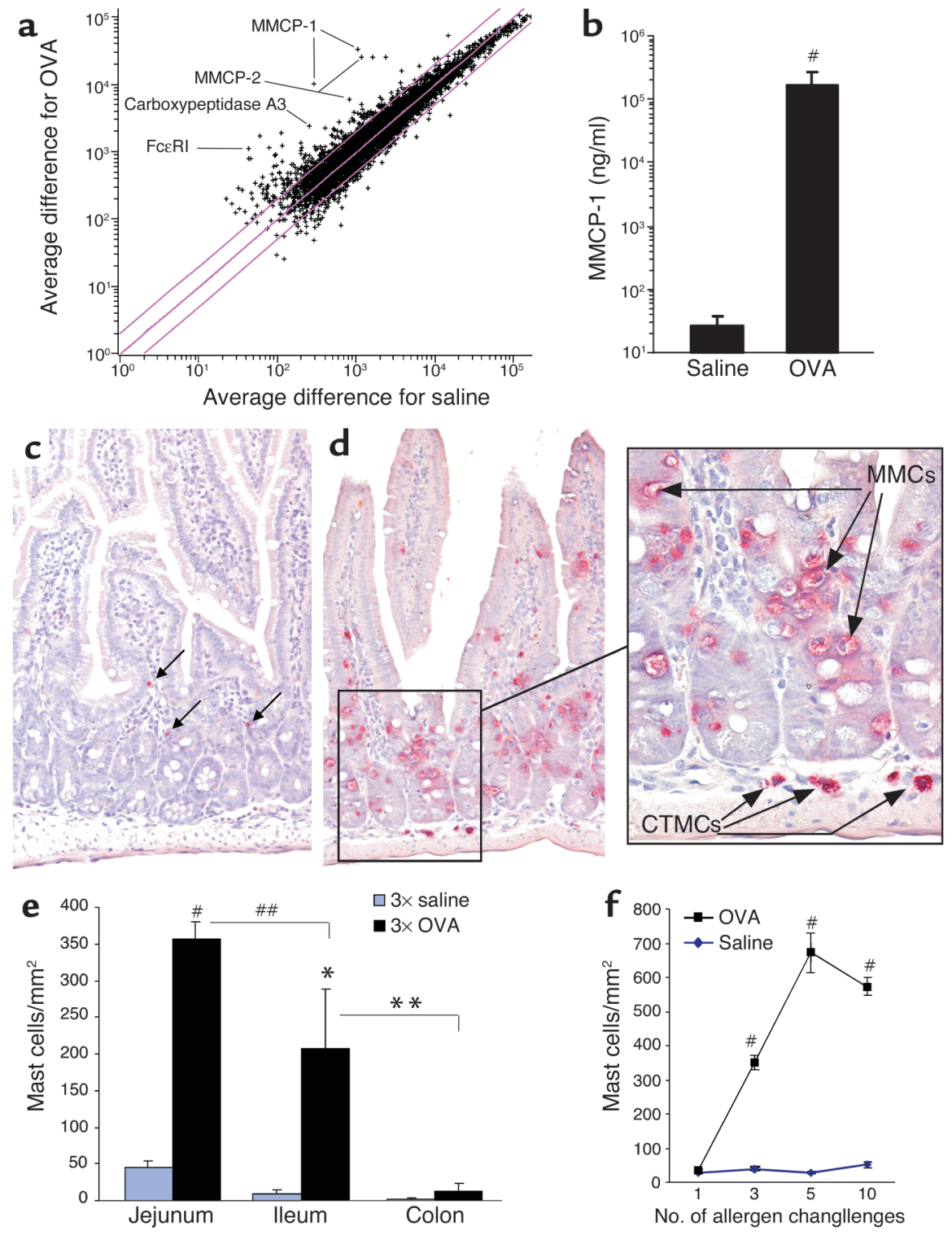

\section{Figure 5}

Mucosal mast cell responses in allergic diarrhea. (a) A scatter plot comparing the average difference in gene expression measured on the murine U74Av2 GeneChip following ten saline or OVA challenges was generated using GeneSpring software. The three lines indicate a twofold increase or twofold decrease compared with the mean. Representative, highly increased mast cell-related genes following diarrhea are indicated. (b) MMCP-1 plasma levels were measured by ELISA following saline or OVA challenges. Representative fields (original magnification, $\times 125)$ of saline-challenged (c) or OVAchallenged (d) jejunum sections illustrate chloroacetate esterase-stained mucosal mast cells (MMCs). A magnification of the crypt region shows strongly degranulated mucosal mast cells (red stain depleted), which contrast sharply with the three connective tissue mast cells (CTMCs) indicated by arrows (original magnification, $\times 500$ ). (e) Mucosal mast cell levels in the jejunum, ileum, and colon following three saline or OVA challenges were assessed by morphometric analysis of chloroacetate esterase-stained cells ( $n=3-4$ mice per group; $\# P<0.0001$; $\left.\# P=0.013 ;{ }^{*} P=0.032 ;{ }^{*} P=0.003\right)$. (f) A kinetic analysis of mast cell recruitment to the jejunum of saline- or OVA-challenged mice $\left({ }^{\#} P<0.0005\right)$.
Allergic diarrhea is IgE mediated. Murine models of active systemic anaphylaxis have demonstrated an important role for IgG-dependent pathways that involve the low-affinity IgG receptor, Fc $\gamma$ RIII $(19,31)$. To test the role of Fc $\gamma \mathrm{RII} / \mathrm{RIII}$, we treated diarrheaprone mice with an anti-Fc $\gamma$ RII/RIII Ab (24G2) or a control Ab (J1.2) 24 hours before an intragastric OVA challenge. Although a similar dose of $24 \mathrm{G} 2$ completely blocked IgG-mediated systemic anaphylaxis in our previous studies (19), it failed to block diarrhea occurrence in the present model, suggesting that diarrhea was not an FcyRIII-mediated process (Figure 7a).

We were next interested in analyzing the role of $\mathrm{IgE}$ in the development of allergic diarrhea. To accomplish this goal, we employed an anti-IgE mAb reagent (EM-95) that works by both blocking IgE and by inducing mast cell refractiveness (it induces mast cell degranulation) (18, 19). Notably, when mice were pretreated with anti-IgE, the allergic diarrhea was markedly attenuated (Figure
$7 b)$. Interestingly, the beneficial effect of this treatment was still present after three consecutive OVA challenges, in accordance with a prolonged anti-IgE Ab half-life. Furthermore, intestinal permeability was significantly reduced in EM-95-treated/OVA-challenged mice when compared with mice receiving the control Ab (Figure 7c).

To further elucidate the role of IgE in allergic diarrhea, we analyzed the role of IgE receptors (32). To assess the importance of activation through FceRI, FceRI gene-deficient mice were subjected to the oral allergen-induced gastrointestinal allergy experimental regime (Figure 7d). After ten intragastric OVA challenges, only $50 \%$ of FceRI KO mice developed diarrhea, whereas all the control mice had diarrhea by the fifth challenge (Figure 7d). Taken together, these observations strongly implicate FceRI-dependent mucosal mast cell activation in the etiology of allergic diarrhea.

Anti-PAF/antiserotonin treatment alleviates allergic diarrhea. To identify which mast cell-associated mediators were 
a
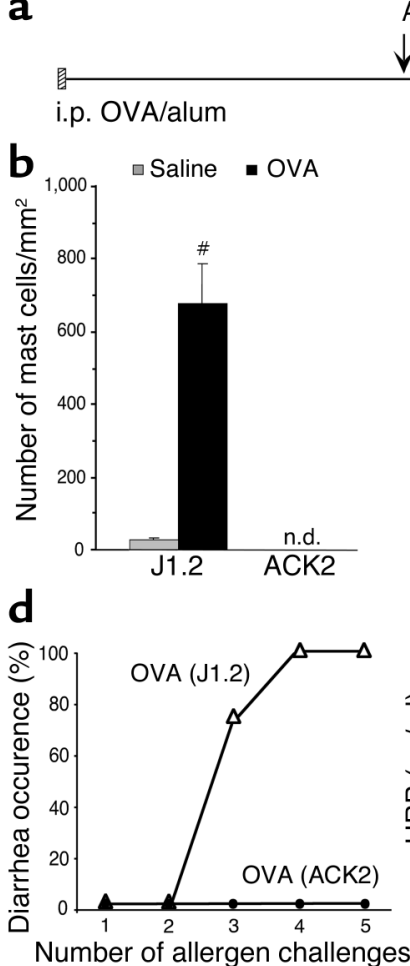

Number of allergen challenges

Figure 6

Absence of diarrhea in mast cell-depleted mice. (a) Following sensitization, mice were treated with a neutralizing ACK2 or a control Ab (J1.2) 24 hours before each intragastric challenge (arrows). Each vertical line represents saline or allergen challenge every 2-3 days. The efficacy of the treatment was assessed by chloroacetate esterase staining for jejunum mast cells (b) and measuring plasma MMCP-1 levels (c) 60 minutes after the fifth saline or OVA challenge in mice treated with either ACK2 or J1.2 ( $n=4$; $\left.{ }^{*} P<0.005 ;{ }^{*} P=0.0026\right)$. (d) Occurrence of diarrhea following five OVA challenges in control $A b(J 1.2)$ or ACK2-treated mice. (e) Intestinal permeability to HRP was measured in an Ussing chamber over 180 minutes (mean \pm SEM; $n=4$ mice/group; $\left.{ }^{*} P=0.01\right)$. n.d., not detected.

responsible for oral allergen-induced diarrhea, mediator antagonists were administered to mice prior to the OVA challenges. Specifically, the drugs targeted either PAF (CV6209), histamine (mepyramine and cimetadine, H1 and $\mathrm{H} 2$ receptor antagonists, respectively), or serotonin receptors (ketanserin, azasetron, and SB 203-186, respectively a $5-\mathrm{HT}_{1 \mathrm{c} / 2}$, a $5-\mathrm{HT}_{3}$, and a $5-\mathrm{HT}_{4}$ receptor antagonist). Notably, none of these drugs alone had any significant effect, as shown in Table 1. A combination of all these drugs, or a combination of PAF and serotonin antagonists, however, significantly suppressed allergic diarrhea (Table 1). Interestingly, antihistamine did not alleviate acute diarrhea, as opposed to its well-documented role in blocking manifestations of mast cell-dependent systemic anaphylaxis (33).

To distinguish the role of these mediators in systemic anaphylaxis and gastrointestinal allergy, we challenged OVA/alum-sensitized mice intravenously with OVA. Notably, treatment with antihistamine alone significantly blocked hypothermia, but treatment with anti- serotonin was totally ineffective (data not shown). Collectively, these results indicate a distinct role for these mediators in the elicitation of systemic (hypothermia) and local gastrointestinal (diarrhea) manifestations.

\section{Discussion}

The recent development of several rodent models of allergic gastrointestinal disease have started to shed important insight on immunological mechanisms leading to these poorly understood disorders $(13,26$, 34-36). To further dissect the mechanisms leading to allergic diarrhea, we developed a model of eosinophilassociated gastrointestinal hypersensitivity involving intragastric allergen challenges in mice previously sensitized to allergen in the presence of the adjuvant alum. Although somewhat similar to the protocol described by Kweon et al., which employed CFA (26), our model displayed a stronger allergic response requiring significantly fewer allergen challenges before onset of diarrhea. The inflammation was not restricted to the large intestine, but involved marked mast cell and eosinophil infiltration in the small intestine. The location of inflammation in different regions of the intestine between these two studies may be due to the use of different adjuvants and sensitization routes (e.g., subcutaneous versus intraperitoneal) that are likely to evoke distinct DC responses. Diarrhea was accompanied by increased intestinal permeability; notably, the increased intestinal permeability persisted for at least 48 hours after antigen challenge even though the diarrhea only occurred acutely following allergen challenge. This indicates that the development of altered intestinal permeability is not by itself responsible for the allergic diarrhea. The occurrence of acute diarrhea, usually within 30 minutes of antigen exposure, the presence of marked intestinal mastocytosis, and mast cell degranulation (detected by histochemical analysis and plasma MMCP-1 levels), strongly suggested a primary type I hypersensitivity reaction.

To definitively demonstrate a critical role for mast cells in allergic diarrhea, we first attempted to induce the experimental regime in mast cell-deficient mice (W/Wv) (37). As observed with C57Bl/6 mice, however, the strain of these mice (WWB6F1) was resistant to the experimental protocol. Therefore, we choose to deplete WT BALB/c mice of mast cells by repeated administration of ACK2 (20). ACK2 (over a period of 2 weeks) was very effective in abrogating intestinal mastocytosis (both connective tissue and mucosal mast cells) and, importantly, completely blocked the allergic diarrhea and increased intestinal permeability. Recognizing that c-kit is not exclusively expressed by mast cells (e.g., it is also expressed by interstitial cells of Cajal), we aimed to prove the involvement of mast cells by other approaches. Indeed, anti-IgE treatment blocked allergic diarrhea. Because the mechanism of anti-IgE is not strictly dependent upon inhibition of mast cell signaling, we also analyzed FceRI gene-targeted mice; these studies supported the involvement of mast cells, primarily 

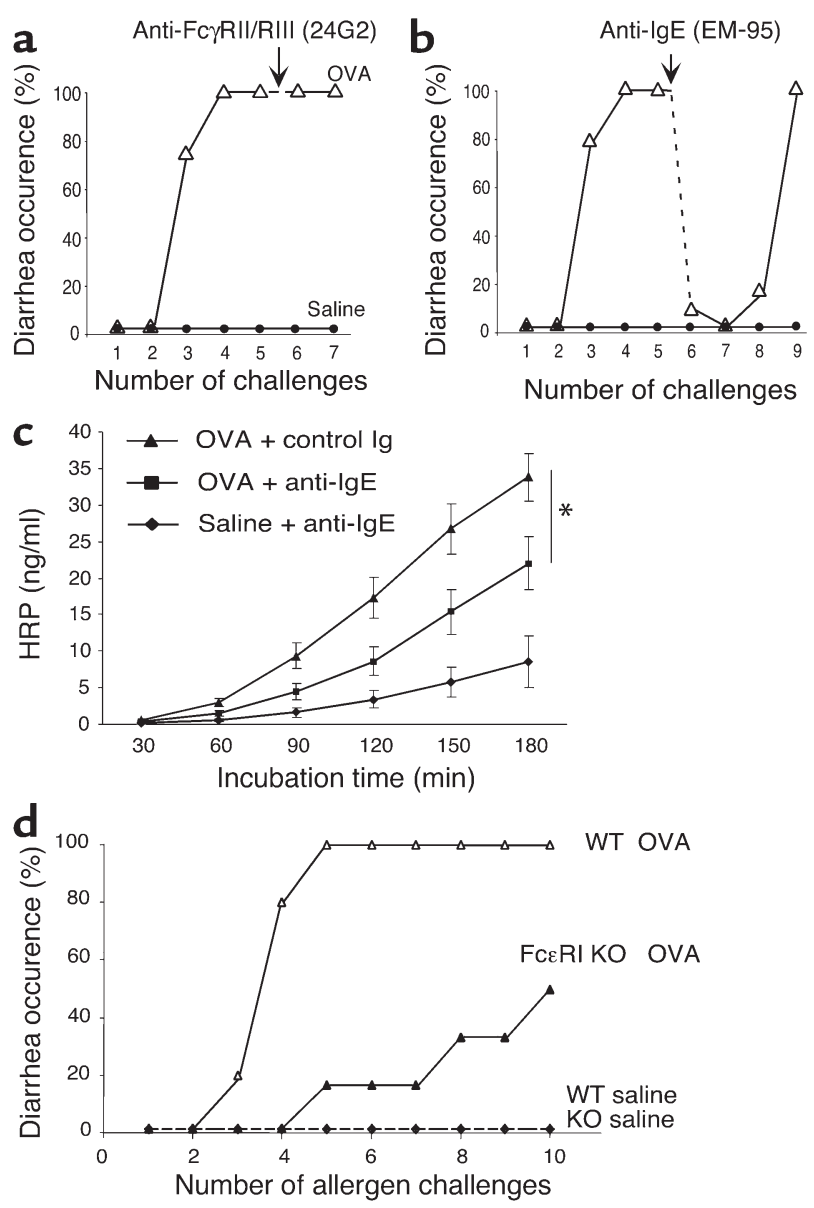

through an IgE-dependent pathway. Previous studies have shown that FcERI-deficient mice are resistant to IgE-dependent passive anaphylaxis $(38,39)$, but can undergo active anaphylaxis by an IgG/FcyRIII-dependent pathway $(19,31,40,41)$. In our model, however, allergen-induced diarrhea was not blocked by an $\mathrm{Ab}$ directed against Fc $\gamma$ RII/III. The ability of FceRI-deficient mice to eventually develop allergic diarrhea indicates that FceRI-independent mechanisms (e.g., Fc $\gamma \mathrm{RI}$, C5a, CD23 pathways) may contribute to gastrointestinal allergy under some circumstances (9).

The necessity to avoid anaphylactic shock without curtailing an effective mast cell response may explain why mast cells exist as several different populations. As opposed to connective tissue mast cells, which contain numerous granules rich in histamine and serotonin, intestinal mucosal mast cells have low content of histamine and serotonin and distinct granule proteases (4, 11,16). Thus, degranulation of mucosal mast cells may only induce local mucosal and epithelial responses leading to diarrhea without provoking a massive release of histamine and serotonin in the bloodstream, where these compounds have potential to trigger life-threatening anaphylactic shock. Indeed, histamine, PAF, and serotonin have all been reported to be released during anaphylaxis, and each of these mediators can directly cause shock if injected into rodents in sufficient quan-

\section{Figure 7}

Allergic diarrhea is IgE mediated. Following two OVA/alum sensitizations, mice were treated with intragastric saline or OVA challenges as depicted in Figure 1a. Twenty-four hours before challenge six (arrow), mice were treated with either an Ab against (a) the lowaffinity IgG receptors FcyRII/RIII (24G2) or (b) with an anti-IgE Ab $(E M-95)\left(n=6-8\right.$ mice; $\left.{ }^{*} P=0.033\right)$. (c) Mice were treated with the EM-95 or GL117 control Ab (mean \pm SEM; $n=4-6$ mice), and intestinal permeability to HRP was measured in an Ussing chamber over 180 minutes. (d) Diarrhea occurrence in FcERI KO mice and WT littermate controls following up to ten intragastric saline or OVA challenges ( $n=6$ and 5 , respectively).

tity $(19,42,43)$. These reports would be consistent with our observation that, despite massive mucosal (but not connective tissue) mast cell degranulation, allergic diarrhea is not accompanied by anaphylactic shock (e.g., hypothermia or death).

While the mechanisms responsible for end organ tissue damage in anaphylaxis have not been clearly elucidated (9), our results suggest that mast cell-derived serotonin in combination with PAF has a central role in mediating allergic diarrhea. The drugs used to block serotonin receptors were unable to discriminate between the different serotonin receptors, but in combination with anti-PAF treatment, ketanserin (a 5- $\mathrm{HT}_{2}$ blocker, sometimes also described as a $5-\mathrm{HT}_{1 \mathrm{c}}$ blocker) (24) was more efficient than each of the two other antiserotonin drugs. Similar inhibition, however, was observed when two antiserotonin drugs that target $5-\mathrm{HT}_{3}$ and $5-\mathrm{HT}_{4}$ receptors were used in combination with anti-PAF. Thus, while serotonin receptor function might display some level of redundancy, these results strongly implicate serotonin in the etiology of allergic diarrhea. Our results are consistent with studies focused on water and electrolyte movement in a rat jejunal perfusion assay that demonstrated involvement of the serotonin receptors $5-\mathrm{HT}_{2}$ and $5-\mathrm{HT}_{3}(44)$. Drugs that block $5-\mathrm{HT}_{3}$ have also been reported to inhibit the

\section{Table 1}

Effect of different antiallergic drug treatments on diarrhea

\section{Drug treatment}

Antihistamine $(\mathrm{H} 1+\mathrm{H} 2)$

Antiserotonin $\left(5-\mathrm{HT}_{1 / 2}+5-\mathrm{HT}_{3}+5-\mathrm{HT}_{4}\right)$

Anti-PAF

All drugs together

Anti-serotonin + antihistamine

Anti-PAF + antihistamine

Anti-PAF + antiserotonin

Anti-PAF + anti-5- $\mathrm{HT}_{1 / 2}$

Anti-PAF + anti-5- $\mathrm{HT}_{3}+5-\mathrm{HT}_{4}$

Anti-PAF + anti-5- $\mathrm{HT}_{3}$

Anti-PAF + anti-5- $\mathrm{HT}_{4}$
Diarrhea occurrence

$10 / 11$

$10 / 11$

$11 / 11$

$1 / 10$

$8 / 8$

$11 / 12$

$0 / 8$

$1 / 11$

$2 / 10$

$9 / 11$

$9 / 11$
All drugs were administered intravenously 20-30 minutes before intragastric challenge, alone or in combination, resulting in a total volume of $200 \mu \mathrm{l}$ per injection. The onset of intestinal anaphylaxis was assessed by the development of acute diarrhea within 45 minutes of allergen challenge. The data are expressed as the number of mice with diarrhea divided by the total number of mice. 
net fluid secretion induced by cholera toxin (25) and colonic transit in rats (45). Interestingly, diarrhea in patients with irritable bowel syndrome is improved by treatment with alosetron, a $5-\mathrm{HT}_{3}$ antagonist (46). Finally, mice deficient in a high-affinity serotonin transporter, which leads to increased serotonin accumulation in the intestinal mucosa, display watery diarrhea and increased colonic motility (47). Collectively, these studies highlight a central role for serotonin in the elicitation of local allergic intestinal permeability. Our results do not rule out the coinvolvement of other mediators, such as MMCP-1, recently implicated in increased intestinal permeability during Trichinella spiralis infection (48).

It is certainly notable that allergic diarrhea occurred by a largely histamine-independent process. Recently, histamine receptors and Th1/Th2 responses have been shown to be dynamically inversely regulated, perhaps as a protective mechanism $(33,49)$. It is interesting to speculate that the histamine-independent development of allergic diarrhea and the absence of systemic anaphylaxis (which has been shown to be histamine dependent) during our experimental regime may be a result of downregulated histamine receptors by the strong experimental Th2 protocol.

Eosinophil-associated gastrointestinal disorders are frequently associated with diarrhea $(2,3)$. In the investigation of gastrointestinal allergy, eosinophilia is often recognized before increases in mast cells are noted (due to their more ready detection by standard histological techniques). In these settings, eosinophils are often implicated in disease pathology; indeed, we have identified a critical effector role for eosinophils in the development of certain manifestations of experimental gastrointestinal allergy (13). Furthermore, the capacity of eosinophil granule proteins (e.g., MBP) to induce mast cell degranulation has been demonstrated recently (29, 50). Experiments with mice containing genetically regulated levels of eosinophils revealed that eosinophils were not critical for the development of allergic diarrhea. Although we have not ruled out a role for eosinophils in other manifestations of disease in our experimental regime, these results suggest that allergic diarrhea is not dependent upon this cell population.

In summary, we have identified the mechanism of experimental oral allergen-induced diarrhea to be critically dependent upon mast cells, IgE, PAF, and serotonin. Although no murine study adequately mimics human disease, we are hopeful that these results provide paradigms for testing in humans. For example, our results highlight the critical role for mast cells in allergic diarrhea, drawing attention to the analysis of this cell type in human gastrointestinal allergic disorders, especially in patients with diarrhea. The identified mechanism also suggests that agents such as anti-IgE, recently approved for the treatment of human asthma, and the c-kit inhibitor imatinib mesylate, recently approved for various malignancies, may have use for gastrointestinal allergy. The finding that allergic diar- rhea is mediated by a mechanism involving classic IgEmediated mast cell activation (unaccompanied by signs of systemic anaphylaxis) prompts us to propose that allergic diarrhea may be better called "intestinal anaphylaxis," at least under certain circumstances.

\section{Acknowledgments}

The authors would like to thank Andrea Lippelman for editorial assistance, Anil Mishra and Simon Hogan for helpful discussions, Frank Austen for critical review of this manuscript, James and Nancy Lee for kindly providing anti-MBP, Dan Friend for guidance on mast cell histochemistry, and Paul Foster and Klaus Matthaei for the eotaxin-1/IL-5 double-deficient mice. This work was supported in part by an American Heart Association Scientist Development grant (to E.B. Brandt), NIH grant K08 AI-50006 (to R.T. Strait), Burroughs Wellcome Fund grant 1002171 (to M.E. Rothenberg), Human Frontier Science Program grant RG 264/99 (to M.E. Rothenberg), International Life Science Institute grant 1000614 (to M.E. Rothenberg), and NIH/NIAID grants R01 AI-42242-05 and R01 AI-45898-03 (to M.E. Rothenberg).

1. Sampson, H.A. 2003. 9. Food allergy. J. Allergy Clin. Immunol. 111(Suppl. 2):S540-S547.

2. Rothenberg, M.E., Mishra, A., Brandt, E.B., and Hogan, S.P. 2001. Gastrointestinal eosinophils in health and disease. Adv. Immunol. 78:291-328.

3. Kweon, M.N., and Kiyono, H. 2003. Eosinophilic gastroenteritis: a problem of the mucosal immune system? Curr. Allergy Asthma Rep. 3:79-85.

4. Crowe, S.E., and Perdue, M.H. 1992. Gastrointestinal food hypersensitivity: basic mechanisms of pathophysiology. Gastroenterology. 103:1075-1095.

5. Lin, R.Y., et al. 2000. Histamine and tryptase levels in patients with acute allergic reactions: an emergency department-based study. J. Allergy Clin. Immunol. 106:65-71.

6. Sampson, H.A., Mendelson, L., and Rosen, J.P. 1992. Fatal and near-fatal anaphylactic reactions to food in children and adolescents. N. Engl. J. Med. 327:380-384.

7. Santos, J., et al. 1999. Characterisation of immune mediator release during the immediate response to segmental mucosal challenge in the jejunum of patients with food allergy. Gut. 45:553-558.

8. Schwartz, L.B., Metcalfe, D.D., Miller, J.S., Earl, H., and Sullivan, T. 1987. Tryptase levels as an indicator of mast-cell activation in systemic anaphylaxis and mastocytosis. N. Engl. J. Med. 316:1622-1626.

9. Yu, L.C., and Perdue, M.H. 2001. Role of mast cells in intestinal mucosal function: studies in models of hypersensitivity and stress. Immunol. Rev. 179:61-73.

10. Bischoff, S.C. 1996. Mucosal allergy: role of mast cells and eosinophil granulocytes in the gut. Baillieres Clin. Gastroenterol. 10:443-459.

11. Gurish, M.F., and Austen, K.F. 2001. The diverse roles of mast cells. J. Exp. Med. 194:F1-F5.

12. Galli, S.J., Maurer, M., and Lantz, C.S. 1999. Mast cells as sentinels of innate immunity. Curr. Opin. Immunol. 11:53-59.

13. Hogan, S.P., et al. 2001. A pathological function for eotaxin and eosinophils in eosinophilic gastrointestinal inflammation. Nat. Immunol. 2:353-360.

14. Mishra, A., Hogan, S.P., Lee, J.J., Foster, P.S., and Rothenberg, M.E. 1999. Fundamental signals that regulate eosinophil homing to the gastrointestinal tract. J. Clin. Invest. 103:1719-1727.

15. Wang, Q., Fang, C.H., and Hasselgren, P.O. 2001. Intestinal permeability is reduced and IL-10 levels are increased in septic IL-6 knockout mice. Am. J. Physiol. Regul. Integr. Comp. Physiol. 281:R1013-R1023.

16. Friend, D.S., et al. 1996. Mast cells that reside at different locations in the jejunum of mice infected with Trichinella spiralis exhibit sequential changes in their granule ultrastructure and chymase phenotype. J. Cell Biol. 135:279-290.

17. Zimmermann, N., et al. 2003. Dissection of experimental asthma with DNA microarray analysis identifies arginase in asthma pathogenesis. J. Clin. Invest. 111:1863-1874. doi:10.1172/JCI200317912.

18. Liu, E., et al. 2002. Anti-peptide autoantibodies and fatal anaphylaxis in NOD mice in response to insulin self-peptides B:9-23 and B:13-23. J. Clin. Invest. 110:1021-1027. doi:10.1172/JCI200215488. 
19. Strait, R.T., Morris, S.C., Yang, M., Qu, X.W., and Finkelman, F.D. 2002. Pathways of anaphylaxis in the mouse. J. Allergy Clin. Immunol. 109:658-668.

20. Grencis, R.K., Else, K.J., Huntley, J.F., and Nishikawa, S.I. 1993. The in vivo role of stem cell factor (c-kit ligand) on mastocytosis and host protective immunity to the intestinal nematode Trichinella spiralis in mice. Parasite Immunol. 15:55-59.

21. Han, L., et al. 1998. Effect of PAF receptor antagonists on adrenocortical secretion induced by ACTH in normal and athymic nude mice. Life Sci. 62:715-726.

22. Makabe-Kobayashi, Y., et al. 2002. The control effect of histamine on body temperature and respiratory function in IgE-dependent systemic anaphylaxis. J. Allergy Clin. Immunol. 110:298-303.

23. Kaneta, S., Yanaguimoto, H., Kagaya, J., Ishizuki, S., and Fujihira, E. 1993. Effects of H2-antihistamines in murine models of immediate hypersensitivity and chronic inflammation. Res. Commun. Chem. Pathol. Pharmacol. 79:167-184.

24. Leysen, J.E., Niemegeers, C.J., Van Nueten, J.M., and Laduron, P.M. 1982. $[3 \mathrm{H}]$ Ketanserin ( $\mathrm{R} 41468$ ), a selective $3 \mathrm{H}$-ligand for serotonin 2 receptor binding sites. Binding properties, brain distribution, and functional role. Mol. Pharmacol. 21:301-314.

25. Ooe, M., Asano, K., Haga, K., and Setoguchi, M. 1993. Effect of Y-25130, a selective 5-HT3 receptor antagonist, on the intestinal fluid secretion in rats. Nippon Yakurigaku Zasshi. 101:299-307.

26. Kweon, M.N., Yamamoto, M., Kajiki, M., Takahashi, I., and Kiyono, H. 2000. Systemically derived large intestinal CD4(+) Th2 cells play a central role in STAT6-mediated allergic diarrhea. J. Clin. Invest. 106:199-206.

27. Field, M. 2003. Intestinal ion transport and the pathophysiology of diarrhea. J. Clin. Invest. 111:931-943. doi:10.1172/JCI200318326.

28. Musch, M.W., et al. 2002. T cell activation causes diarrhea by increasing intestinal permeability and inhibiting epithelial $\mathrm{Na}+\mathrm{K}+$-ATPase. J. Clin. Invest. 110:1739-1747. doi:10.1172/JCI200215695.

29. Piliponsky, A., Gleich, G., Bar, I., and Levi-Schaffer, F. 2002. Effects of eosinophils on mast cells: a new pathway for the perpetuation of allergic inflammation. Mol. Immunol. 38:1369-1372.

30. Takatsu, K. 1995. Interleukin-5: an overview. Cancer Treat. Res. 80:187-208.

31. Dombrowicz, D., et al. 1997. Absence of Fc epsilonRI alpha chain results in upregulation of Fc gammaRIII-dependent mast cell degranulation and anaphylaxis. Evidence of competition between Fc epsilonRI and Fc gammaRIII for limiting amounts of FcR beta and gamma chains. J. Clin. Invest. 99:915-925.

32. Kinet, J.P. 1999. The high-affinity IgE receptor (Fc epsilon RI): from physiology to pathology. Annu. Rev. Immunol. 17:931-972.

33. Akdis, C.A., and Blaser, K. 2003. Histamine in the immune regulation of allergic inflammation. J. Allergy Clin. Immunol. 112:15-22.

34. Xu, X., et al. 2002. Mast cells involvement in the inflammation and fibrosis development of the TNBS-induced rat model of colitis. Scand. J. Gastroenterol. 37:330-337.

35. Li, X.M., Schofield, B.H., Huang, C.K., Kleiner, G.I., and Sampson, H.A.
1999. A murine model of IgE-mediated cow's milk hypersensitivity. J. Allergy Clin. Immunol. 103:206-214.

36. Dombrowicz, D., et al. 2001. Role of the high affinity immunoglobulin E receptor in bacterial translocation and intestinal inflammation. J. Exp. Med. 193:25-34.

37. Wershil, B.K. 2000. IX. Mast cell-deficient mice and intestinal biology. Am. J. Physiol. Gastrointest. Liver Physiol. 278:G343-G348.

38. Dombrowicz, D., Flamand, V., Brigman, K.K., Koller, B.H., and Kinet, J.P. 1993. Abolition of anaphylaxis by targeted disruption of the high affinity immunoglobulin E receptor alpha chain gene. Cell. 75:969-976.

39. Takai, T., Li, M., Sylvestre, D., Clynes, R., and Ravetch, J.V. 1994. FcR gamma chain deletion results in pleiotrophic effector cell defects. Cell. 76:519-529.

40. Dombrowicz, D., et al. 1998. Allergy-associated FcRbeta is a molecular amplifier of IgE- and IgG-mediated in vivo responses. Immunity. 8:517-529.

41. Miyajima, I., et al. 1997. Systemic anaphylaxis in the mouse can be mediated largely through IgG1 and Fc gammaRIII. Assessment of the cardiopulmonary changes, mast cell degranulation, and death associated with active or IgE- or IgG1-dependent passive anaphylaxis. J. Clin. Invest. 99:901-914.

42. Vaz, N.M., de Souza, C.M., Hornbrook, M.M., Hanson, D.G., and Lynch, N.R. 1977. Sensitivity to intravenous injections of histamine and serotonin in inbred mouse strains. Int. Arch. Allergy Appl. Immunol. 53:545-554.

43. Ishii, S., et al. 1998. Impaired anaphylactic responses with intact sensitivity to endotoxin in mice lacking a platelet-activating factor receptor. J. Exp. Med. 187:1779-1788.

44. Mourad, F.H., O'Donnell, L.J., Ogutu, E., Dias, J.A., and Farthing, M.J. 1995. Role of 5-hydroxytryptamine in intestinal water and electrolyte movement during gut anaphylaxis. Gut. 36:553-557.

45. Haga, K., Asano, K., Fukuda, T., and Kobayakawa, T. 1995. The function of 5-HT3 receptors on colonic transit in rats. Obes. Res. 3(Suppl. 5):801S-810S.

46. Cremonini, F., Delgado-Aros, S., and Camilleri, M. 2003. Efficacy of alosetron in irritable bowel syndrome: a meta-analysis of randomized controlled trials. Neurogastroenterol. Motil. 15:79-86.

47. Chen, J.J., et al. 2001. Maintenance of serotonin in the intestinal mucosa and ganglia of mice that lack the high-affinity serotonin transporter: abnormal intestinal motility and the expression of cation transporters. J. Neurosci. 21:6348-6361.

48. McDermott, J.R., et al. 2003. Mast cells disrupt epithelial barrier function during enteric nematode infection. Proc. Natl. Acad. Sci. U. S. A. 100:7761-7766.

49. Jutel, M., et al. 2001. Histamine regulates T-cell and antibody responses by differential expression of $\mathrm{H} 1$ and $\mathrm{H} 2$ receptors. Nature. 413:420-425.

50. Piliponsky, A.M., Gleich, G.J., Nagler, A., Bar, I., and Levi-Schaffer, F. 2003. Non-IgE-dependent activation of human lung- and cord bloodderived mast cells is induced by eosinophil major basic protein and modulated by the membrane form of stem cell factor. Blood. 101:1898-1904. 